\title{
Genotyping the GALNT14 gene by joint analysis of two linked single nucleotide polymorphisms using liver tissues for clinical and geographical comparisons
}

\author{
KUNG-HAO LIANG ${ }^{1}$, PEI-CHING YANG $^{1}$ and $\mathrm{CHAU-TING} \mathrm{YEH}^{1,2}$ \\ ${ }^{1}$ Liver Research Center, Chang Gung Memorial Hospital, Taipei; ${ }^{2}$ Molecular Medicine Research Center, \\ Chang Gung University, Taoyuan 10507, Taiwan, R.O.C.
}

Received October 31, 2013; Accepted July 23, 2014

DOI: $10.3892 / 01.2014 .2507$

\begin{abstract}
A GALNT14 single nucleotide polymorphism, rs9679162, has recently been found to be capable of predicting chemotherapy responses in patients with far-advanced hepatocellular carcinoma (HCC). In the present study, a novel assay was designed and genotyping was performed on 244 surgically removed liver tissues. This assay employed two polymerase chain reaction (PCR)-generated restriction enzyme sites to simultaneously determine the genotypes of two adjacent single nucleotide polymorphisms (SNPs), rs9679162 and rs6752303, on the GALNT14 gene. Genotypes determined by this assay reached $100 \%$ concordance with those detected by the direct sequencing method. Clinical analysis showed that the TT genotype of rs9679162 was lower in percentage among patients with virus-originated HCC compared with those with non-viral HCC (22.57 vs. $47.06 \%$, respectively; $\mathrm{P}=0.023)$. The proportion of the TT genotype in the 244 HCC patients $(24.18 \%)$ did not deviate significantly from those of two public-domain (HapMap) Chinese cohorts from Denver, Colorado, USA (28.44\%) and Beijing, China (30.15\%) ( $\mathrm{P}>0.05)$. The proportion of the TT genotype was significantly higher in Japanese and African populations (42.11-54.55\%; $\mathrm{P}<0.0001)$ but significantly lower in an Italian cohort $(7.84 \% ; \mathrm{P}=0.0004)$. In conclusion, the novel PCR-generated double restriction enzyme sites method could correctly determine the genotypes of two target SNPs in GALNT14 in liver tissues. The TT genotype was associated with the non-viral etiology of HCC. A marked variation in ethnicity was found for the distribution of this genotype.
\end{abstract}

Correspondence to: Dr Kung-Hao Liang and Professor Chau-Ting Yeh, Liver Research Center, Chang Gung Memorial Hospital, 199 Tung Hwa North Road, Taipei 10507, Taiwan, R.O.C.

E-mail: kunghao@gmail.com

E-mail: chautingy@gmail.com

Key words: glycosyltransferase, hepatocellular carcinoma, single nucleotide polymorphism, non-viral etiology, restriction enzyme

\section{Introduction}

As an aggressive cancer, hepatocellular carcinoma (HCC) is the third leading cause of cancer-related mortality and the fifth most common solid malignant tumor (1). Early-stage HCC can be treated by surgical resection, while late-stage HCC patients are often treated by sorafenib or combination chemotherapy (2). Viral infection is the major cause of HCC; in Asia, hepatitis $\mathrm{B}$ virus (HBV) is the predominant cause, while in the Western world, hepatitis C virus (HCV) is the major cause (3).

Recently, a single nucleotide polymorphism (SNP) on GALNT14 has been repetitively shown to correlate with the therapeutic responses of combination chemotherapy in independent cohorts of patients with far-advanced HCC, and the TT genotype of the SNP, rs9679162, was correlated with a good post-chemotherapy prognosis $(2,4)$. The genotyping technique in these studies followed the traditional concept, using peripheral blood cells to provide chromosomal DNA and polymerase chain reaction followed by direct sequencing to determine genotypes. To facilitate future studies regarding the association between this genotype and other clinical parameters, a more convenient assay was necessary. The assay required the capability to process one or a few samples (in cases where a few patients were to be assessed per day, for clinical purposes) at low costs, while providing accurate results promptly. The assay required the capability to use tissue-derived chromosomal DNA for genotyping for retrospective studies. Additionally, it should be able to be conducted in medical facilities lacking sequencing machines, as HCC is prevalent in a number of third world countries (5).

The identification of restriction enzymes capable of recognizing and cleaving DNA at specific sites has been a cornerstone of modern biotechnology (6). Genomic DNA digested by restriction enzymes becomes DNA fragments of varied lengths, creating a personalized signature called restriction fragment length polymorphisms (RFLPs). Prior to the widespread use of high-throughput sequencing and genotyping methods, RFLP was one of the major assays for pinpointing genomic regions responsible for various phenotypic traits (7). This technology has led toward the discovery of the CFTR gene, the first disease-bearing gene ever identified by positional cloning $(8,9)$. The method has also been used 
in various clinical assays, including the diagnosis of sickle cell anemia (10).

A variety of SNP assays, including the TaqMan and fluorescence polarization assays, have also been developed (11). One shared characteristic of these assays is the requirement of batches of samples for providing large enough numbers of signals for each of the three genotypes. The signals are then used to delineate the genotype-specific intensity distribution 'on-the-fly', in other words, an unsupervised base-calling technique. Such a platform was found to be suitable in the validation stage for handling a large number of pre-collected samples, however, it was not found to be practical for clinical use considering the daily fluctuations of patient numbers (12). To prepare for future clinical use, a practical, low-cost assay that could be used in a small hospital of a remote village, as well as in large urban medical centers, was developed in the present study. The assay was performed on surgically resected liver tissues, and the derived GALNT14 genotypes were correlated with the clinical data of the HCC patients. Finally, the geographical distributions of the genotypes were examined.

\section{Materials and methods}

Patients and clinical data. This study was conducted under the approval of the Institutional Review Board of Chang Gung Memorial Hospital, Taiwan. All study subjects were adults and provided written informed consent. A total of 244 patients with HCC treated by surgical resection were included, and their surgical specimens were retrieved from the Tissue Bank of Chang Gung Medical Center. Samples were obtained from the non-tumorous sections of the surgical specimens. All samples were frozen at $-70^{\circ} \mathrm{C}$ immediately after surgical resection, until use. HBV was diagnosed if the HBV surface antigen was detected in the patient's peripheral blood. HCV was diagnosed if anti-HCV antibody was detected.

Design of the polymerase chain reaction (PCR)-generated double restriction enzyme sites-RFLP assay. The basic concept behind the proposed assay was to incorporate the target bi-allelic SNP as part of an artificially-introduced restriction enzyme cutting site. Together with adjacent nucleotide bases, one allele of the SNP could constitute a restriction enzyme recognizable sequence, while the other allele could not. As a consequence, samples with distinct SNP alleles manifested as distinct length polymorphisms following restriction enzyme digestion.

The genetic engineering method was employed to introduce sequence signatures artificially. The assay was based on nested PCR. A first-step PCR was designed to amplify the DNA fragment containing the target SNPs without any naturally occurring restriction enzyme cutting sites. The second-step PCR employed a set of specially designed primers targeted to the first amplicons to introduce desired sequence signatures, which were recognizable by restriction enzymes for allele-specific cuttings.

Accordingly, an assay was designed to simultaneously genotype two adjacent and tightly linked SNPs in the GALNT14 gene; each was shown to correlate with the chemotherapy responses of patients with far-advanced HCC (4). GALNT14 resides on chromosome 2, and the two
Table I. Primer sequences for the restriction fragment length polymorphism genotyping assays.

Primer sequence $\mathrm{Tm},{ }^{\circ} \mathrm{C}$

Outer primer

TCACGAGGCCAACATTCTAG

58.9

TTAGATTCTGCATGGCTCAC

Inner primer

GAAAGCAAAGAGATATATATAACGTCT

59.2

ACCACCTTCCCCTTATTCACCTG

66.2

Tm, temperature.

Table II. A look-up table for interpreting the band patterns of the proposed assay.

A, rs9679162

\begin{tabular}{lcccc}
\hline & & \multicolumn{3}{c}{ Genotype $^{\mathrm{a}}$} \\
\cline { 3 - 5 } RE & Band & TT (AA) & TG (AC) & GG (CC) \\
\hline \multirow{2}{*}{ BsmAI cut } & Upper & + & + & - \\
& Lower & - & + & + \\
\hline
\end{tabular}

B, rs6752303

\begin{tabular}{lcccc}
\hline & & \multicolumn{3}{c}{ Genotype $^{\mathrm{a}}$} \\
\cline { 3 - 5 } RE & Band & CC (GG) & CT (GA) & TT (AA) \\
\hline \multirow{2}{*}{ BspMI cut } & Upper & - & + & + \\
& Lower & + & + & - \\
\hline
\end{tabular}

${ }^{\mathrm{a}}$ Genotypes in parentheses are bases in the antisense strand. RE, restriction enzyme.

SNPs, rs9679162 and rs6752303, are in the intronic region of the gene. A set of outer primers was designed to amplify a 172-base amplicon containing the two SNPs (Table I). No endogenous restriction sites were found in the amplicon. The inner primers were then used to introduce two cutting sites of BsmAI and BspMI (GTCTC and ACCTGC respectively), which were formed partly by the primer and partly by rs9679162 and rs6752303 (Fig.1). The second amplicon had a length of 80 bases. The allele types at the site of the SNP were essential in determining whether the cutting could proceed, resulting in fragments ( $\sim 55$ bases). The cut and uncut fragments manifested as lower and upper bands in the gel image of electrophoresis respectively. A look-up table (Table II) described how genotypes can be defined by the band patterns.

Genomic DNA preparation and the first PCR amplification. Genomic DNA was extracted from clinical samples using QIAamp ${ }^{\circledR}$ DNA Mini and Blood Mini kits (Qiagen, 

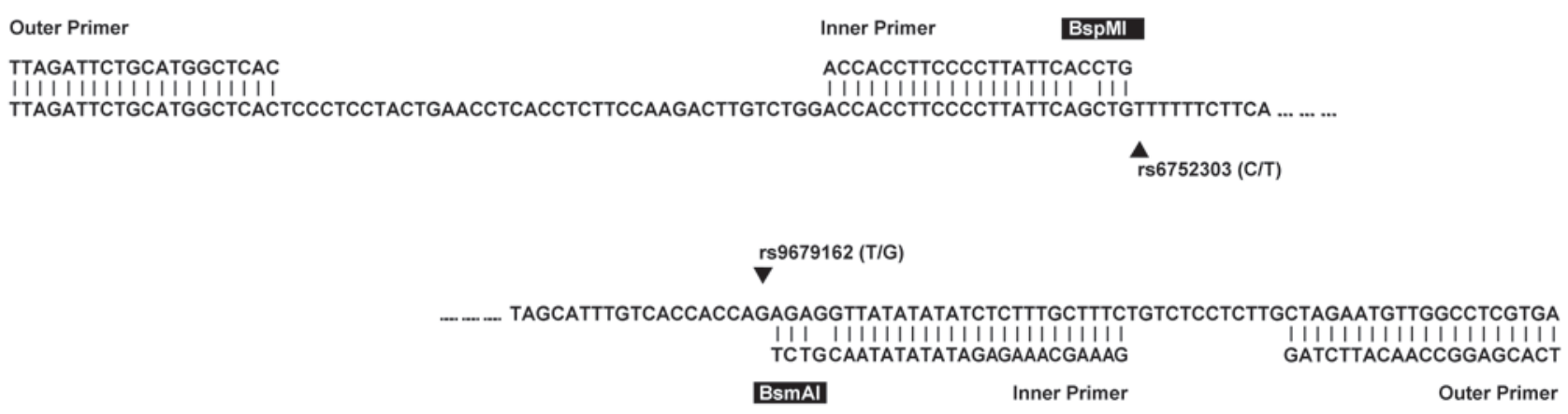

Figure 1. Polymerase chain reaction (PCR)-generated double restriction enzyme sites genotyping assay. The central sequence was the reference genomic DNA sequence. This assay was a nested PCR assay where two primer sets, the outer and inner primers, were used. Each of the inner primers had one base mismatch to the reference sequence for creating a restriction site. The cutting site of BsmAI (GTCTC) was created if the allele type on rs9679162 was G (corresponding to $\mathrm{C}$ in the other strand). The cutting site of BspMI (ACCTGC) was created if the allele type on rs6752303 was C.

Düsseldorf, Germany). DNA amplification was performed in PCR reaction mixture consisting of genomic DNA (5 $\mu 1)$, Taq DNA polymerase 2.0 Master Mix Red $\left(\mathrm{MgCl}_{2}, 1.5 \mathrm{mM}\right.$; $25 \mu \mathrm{l}$; Ampliqon, Glostrup, Denmark), the first set of primers $(10 \mu \mathrm{M}, 0.25 \mu \mathrm{l}$ each; Table I) and water $(19.5 \mu \mathrm{l})$. PCR was carried out for 35 cycles under the following conditions: Initial denaturation at $94^{\circ} \mathrm{C}$ for $5 \mathrm{~min}$, denaturation at $94^{\circ} \mathrm{C}$ for $1 \mathrm{~min}$, annealing at $55^{\circ} \mathrm{C}$ for $1 \mathrm{~min}$ and extension at $72^{\circ} \mathrm{C}$ for $1 \mathrm{~min}$, followed by a final extension step at $72^{\circ} \mathrm{C}$ for $10 \mathrm{~min}$.

Second PCR amplification. The reaction mixture of the second PCR amplification comprised the first PCR amplicon (i.e., the product of the previous step; $0.1 \mu \mathrm{l}$ ), Taq DNA polymerase 2.0 Master Mix Red $\left(\mathrm{MgCl}_{2}, 1.5 \mathrm{mM} ; 25 \mu \mathrm{l}\right)$, the second set of primers $(10 \mu \mathrm{M}, 0.25 \mu \mathrm{l}$ each; Table $\mathrm{I})$, and water $(24.5 \mu \mathrm{l})$. PCR was performed for 20 cycles under the following conditions: Initial denaturation at $94^{\circ} \mathrm{C}$ for $5 \mathrm{~min}$, denaturation at $94^{\circ} \mathrm{C}$ for $1 \mathrm{~min}$, annealing at $55^{\circ} \mathrm{C}$ for $1 \mathrm{~min}$ and extension at $72^{\circ} \mathrm{C}$ for $1 \mathrm{~min}$, followed by a final extension step at $72^{\circ} \mathrm{C}$ for $10 \mathrm{~min}$.

Restriction enzyme digestion and gel electrophoresis. The samples were then digested by restriction enzymes. The reaction mixture comprised the second amplicon $(3 \mu 1)$, 10X buffer $(2 \mu \mathrm{l})$, restriction enzymes BsmAI or Bsp MI (1 $\mu \mathrm{l})$ (New England Biolab, Ipswich, MA, USA) and water (14 $\mu \mathrm{l}$ ). Incubation temperatures were $55^{\circ} \mathrm{C}$ for $B s m A I$ and $37^{\circ} \mathrm{C}$ for $B s p$ MI. The incubation time was $2 \mathrm{~h}$. The lengths of the DNA fragments were analyzed by a subsequent electrophoresis. This was performed by loading the BsmAI- or BspMI-treated samples $(15 \mu \mathrm{l})$ into wells of $2.5 \%$ superfine resolution ${ }^{\mathrm{TM}}$ agarose gel (Amresco, Solon, OH, USA), using $50 \mathrm{~V}$ for $60 \mathrm{~min}$. Genotypes were then defined based on the gel image.

Evaluation of assay accuracy. Sanger sequencing was performed to the first amplicon. The sequencing-derived genotypes were compared with those obtained by the proposed assay.

Statistical and data analysis. The genotypes were correlated with the clinical data of the subjects. $\chi^{2}$ tests were used to compare the categorical variables, including the genotype, gender and presence of cirrhosis, with respect to the TT and non-TT genotypes. Comparisons of numerical variables were performed by two sample t-tests assuming unequal variance. All P-values reported here are two-tailed. SPSS 12.0 software (SPSS, Inc., Chicago, IL, USA) was used for the aforementioned analysis. The public domain HapMap genotype counts were obtained from the official website (http://hapmap.ncbi.nlm.nih.gov/) on Oct 11, 2013, in order to facilitate the analysis (13). The Wellcome Trust Case-Control Consortium (WTCCC) data were downloaded from the European Genome-phenome Archive (EGA) at https://www.ebi.ac.uk/ega/ with permission from the WTCCC (14).

\section{Results}

The genotypes of rs9679162 and rs6752303 obtained from the proposed assay and the conventional Sanger sequencing were identical, reaching a concordance rate of $100 \%$ in the 244 subjects. Fig. 2 shows examples of the gel images of five subjects. Homozygous and heterozygous genotypes were manifested as different band patterns. The genotypes of the two adjacent SNPs were highly associated (linkage disequilibrium, $\left.\mathrm{r}^{2}=0.984\right)$.

The HCC subjects were of either viral (HBV and/or HCV) or non-viral etiologies (Table III). By comparing the clinical data, it was found that the TT type was under-represented in the viral subgroup in comparison with the non-viral subgroup ( $\mathrm{P}=0.0231)$. A subsequent stratification of the viral groups showed that the HBV and HCV subgroups had a higher percentage of the non-TT genotype compared with the non-viral HCC subgroup $(\mathrm{P}=0.0268$ and $\mathrm{P}=0.0331$, respectively). No other associations between genotypes and clinical parameters were observed (Table III). The viral/non-viral etiology did not correlate with a history of alcoholism $(\mathrm{P}=0.750)$. No significant deviations from the Hardy-Weinberg equilibrium were found in either the viral or non-viral HCC subgroups (Table IV).

Geographical distributions of the genotypes were conducted by comparison between the present data and the HapMap data in the public domain (Table IV). The proportion of the TT genotype in the patients with HCC in the present study (24.18\%) did not deviate significantly from 
Table III. Clinical parameters of early-stage HCC patients.

\begin{tabular}{|c|c|c|c|}
\hline Parameter & rs9679162 TT & rs9679162 non-TT & P-value \\
\hline Patient number & 59 & 185 & \\
\hline Age, years & $54.54 \pm 15.04$ & $53.94 \pm 14.37$ & 0.786 \\
\hline Male gender & $48(81.36)$ & $147(79.46)$ & 0.853 \\
\hline \multicolumn{4}{|l|}{ Etiology } \\
\hline HBV & $47(79.66)$ & $158(85.41)$ & 0.253 \\
\hline $\mathrm{HCV}$ & $9(15.25)$ & $36(19.46)$ & 0.458 \\
\hline HBV-HCV co-infection & $5(8.47)$ & $19(10.27)$ & 0.678 \\
\hline Non-viral & $8(13.56)$ & $9(4.86)$ & 0.023 \\
\hline Alcoholism history & $25(42.37)$ & $57(30.81)$ & 0.331 \\
\hline Cirrhosis & $35(59.32)$ & $99(53.51)$ & 0.548 \\
\hline Ascities & $5(8.47)$ & $16(8.65)$ & 0.955 \\
\hline \multicolumn{4}{|l|}{ Biochemical analysis } \\
\hline $\mathrm{AFP}, \mathrm{n} / \mathrm{mL}$ & $1876.54 \pm 6735.52$ & $10104.53 \pm 49077.56$ & 0.054 \\
\hline Albumin, g/dL & $3.93 \pm 0.65$ & $3.92 \pm 0.65$ & 0.935 \\
\hline Bilirubin, mg/dL & $1.68 \pm 2.94$ & $1.20 \pm 1.16$ & 0.224 \\
\hline Creatinine, $\mathrm{mg} / \mathrm{dL}$ & $1.18 \pm 0.66$ & $1.25 \pm 1.41$ & 0.583 \\
\hline AST, U/l & $82.09 \pm 77.79$ & $80.63 \pm 115.76$ & 0.914 \\
\hline ALT, U/1 & $76.60 \pm 79.00$ & $79.95 \pm 108.51$ & 0.804 \\
\hline Prothrombin time, sec & $12.24 \pm 1.34$ & $12.95 \pm 8.08$ & 0.259 \\
\hline
\end{tabular}

Categorical data is presented as n (\%) and compared by Pearson's $\chi^{2}$ test. Quantitative data is presented as the mean \pm standard deviation and compared by two sample t-test assuming unequal variance. HBV, hepatitis B virus; HCV, hepatitis C virus; AFP, $\alpha$-fetoprotein; AST, aspartate aminotransferase; ALT, alanine aminotransferase.

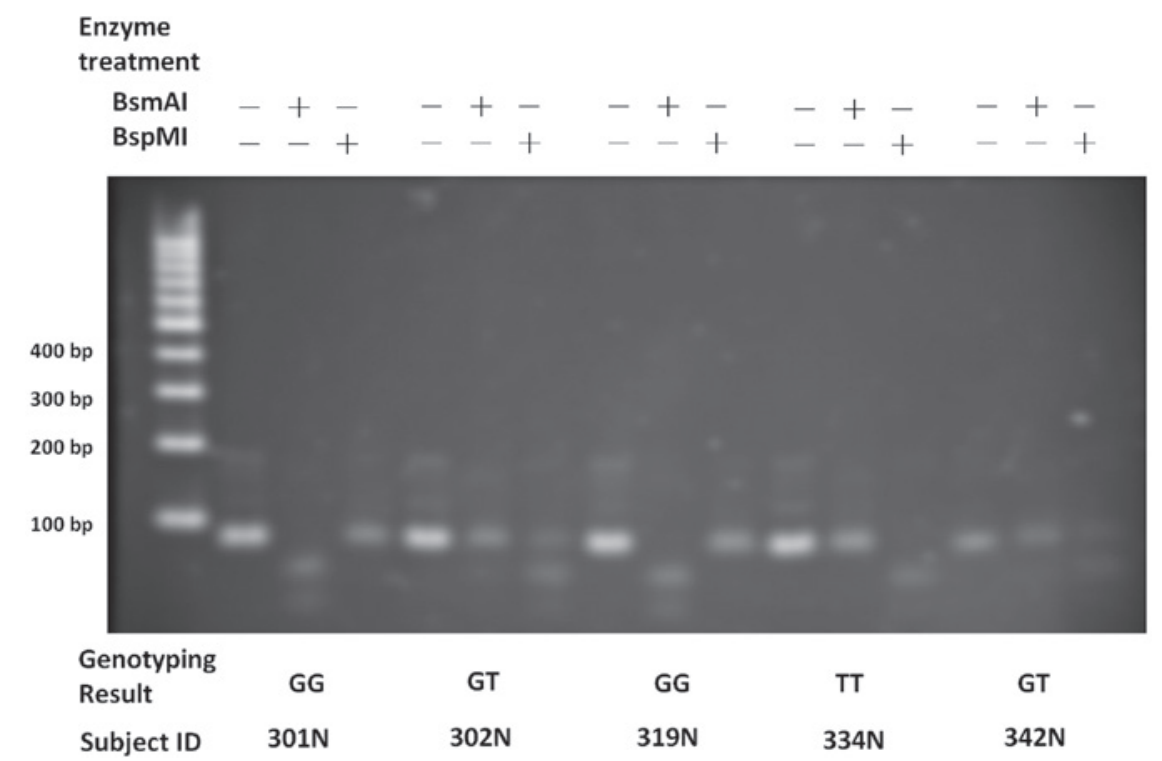

Figure 2. Example gel images of the proposed assay. Genotypes were indicated by the appearance of upper and lower bands according to Table II.

those of two Chinese cohorts from Denver, Colorado, USA (28.44\%) and Beijing, China (30.15\%) ( $>0.05$ for each). The proportion of the TT genotype was significantly higher in Japanese populations from Tokyo (46.02\%) and in three African populations (Kenya, 54.55\%; Nigeria, $48.30 \%$; and African ancestry in USA, 42.11\%) (all $\mathrm{P}<0.0001$ ). Notably, the proportions were significantly lower in cohorts of European descendants, including the Toscani, Italian cohort (7.84\%; $\mathrm{P}=0.0004)$, Utah residents with Northern and Western European ancestry $(12.39 \%$; $\mathrm{P}=0.0097)$, the British 1958 birth cohort $(15.76 \% ; \mathrm{P}=0.0010)$ and the UK National blood service cohort $(17.01 \% ; \mathrm{P}=0.0063)$. 
Table IV. Proportions of rs9679162 genotype in various subgroups.

\begin{tabular}{|c|c|c|c|c|c|}
\hline Subgroups & TT, $\%$ & Non-TT, \% & $\begin{array}{l}\text { Subgroup subject } \\
\text { number }\end{array}$ & $\begin{array}{l}\text { Current study vs. } \\
\text { public data }\end{array}$ & $\begin{array}{l}\text { HWE } \\
\text { P-value }\end{array}$ \\
\hline \multicolumn{6}{|l|}{$\mathrm{HCC}$} \\
\hline Viral & 22.57 & 77.43 & 226 & & 0.5659 \\
\hline Non-viral & 47.06 & 52.94 & 17 & & 0.6446 \\
\hline Total & 24.18 & 75.82 & 244 & & 0.7790 \\
\hline \multicolumn{6}{|l|}{ HapMap } \\
\hline Luhya in Webuye, Kenya & 54.55 & 45.45 & 110 & $<0.0001$ & 0.0471 \\
\hline Yoruba in Ibadan, Nigeria & 48.30 & 51.70 & 147 & $<0.0001$ & 0.8995 \\
\hline Japanese in Tokyo, Japan & 46.02 & 53.98 & 113 & $<0.0001$ & 0.9959 \\
\hline African ancestry in Southwest USA & 42.11 & 57.89 & 57 & $<0.0001$ & 0.9999 \\
\hline Mexican ancestry in Los Angeles, California & 36.21 & 63.79 & 58 & 0.0647 & 0.6739 \\
\hline Han Chinese in Beijing, China & 30.15 & 69.85 & 136 & 0.2138 & 0.7203 \\
\hline Chinese in Metropolitan Denver, Colorado & 28.44 & 71.56 & 109 & 0.4081 & 0.9005 \\
\hline Maasai in Kinyawa, Kenya & 25.00 & 75.00 & 156 & 0.8705 & 0.9873 \\
\hline Gujarati Indians in Houston, Texas & 16.83 & 83.17 & 101 & 0.1294 & 0.7804 \\
\hline $\begin{array}{l}\text { Utah residents with Northern and Western } \\
\text { European ancestry from the Centre d'Etude } \\
\text { du Polymorphisme Humain collection }\end{array}$ & 12.39 & 87.61 & 113 & 0.0097 & 0.4639 \\
\hline Toscani in Italia & 7.84 & 92.16 & 102 & 0.0004 & 0.0927 \\
\hline \multicolumn{6}{|l|}{ WTCCC } \\
\hline British 1958 birth cohort & 15.76 & 84.24 & 1504 & 0.0010 & 0.3033 \\
\hline UK national blood service & 17.01 & 82.99 & 1499 & 0.0063 & 0.9470 \\
\hline
\end{tabular}

${ }^{a}$ HWE, Hardy-Weinberg equilibrium; WTCCC, The Wellcome Trust Case-Control Consortium.

\section{Discussion}

Reliable genetic biomarkers for patients with HCC could offer critical information for personal preventive and therapeutic strategies, and GALNT14-rs9679162 has been shown to have such a potential $(2,4)$. The GALNT family of glycosyltransferases has long been indicated to be involved in the onset and progression of various cancers, including $\mathrm{HCC}$, although the molecular mechanisms remain largely elusive (15-19). GALNT14 has been shown to be involved in the glycosylation of multiple cellular substrates, including death receptors, DR4 and DR5 (20). The mRNA level has been shown to positively correlate with cancer cell sensitivity to DR4 and DR5 agonists $(20,21)$. It has also been found that GALNT14 proteins are more abundant in breast carcinoma compared with normal tissues, but that the expression levels decrease in more advanced stages of cancer (22).

In the present study, a comparison of genotype distributions of various HCC etiologies revealed that the TT genotype, previously reported to indicate a good post-chemotherapy prognosis, was present in a smaller proportion in the viral HCC subgroup (22.57\%) compared with the non-viral HCC subgroup $(47.06 \%, \mathrm{P}=0.0231)$. The reduced percentage of the TT genotype in the viral HCC subgroup suggested that it may impart a lower risk of HCC among chronic HBV and $\mathrm{HCV}$ patients. As the TT genotype was associated with a good chemotherapy response, we hypothesized that HCC cells possessing this genotype were more susceptible to chemotherapy agents owing to the link between the GALNT14 and apoptosis pathways (20). As such, the hepatocytes of TT genotype could be more vulnerable under HBV or HCV infection and thus, less easily progress to liver cancer. Such a protective role appeared to apply to $\mathrm{HBV}$ and $\mathrm{HCV}$, as the two subgroups had reduced TT percentages.

Comparing the current study to the public-domain HapMap data, it was found that the Japanese population had a higher percentage of the TT genotype (Table IV). Notably, Japanese patients with advanced HCC have been reported to have high response rates to interferon and 5-fluorouracil combination therapy (23). We hypothesize that the high proportion of the TT genotype in Japanese patients may underlie the high response rates in this country.

In summary, the current study presented a novel genotyping method through the use of PCR-generated double restriction enzyme sites. This method could correctly genotype two linked SNPs in GALNT14. Additionally, the TT percentage of rs9679162 was lower in the viral subgroups of HCC.

\section{Acknowledgements}

The authors would like to thank Ms. Hui-Chin Chen and Ms. Chung-Yin Wu in the Liver Research Center, Chang Gung Memorial Hospital, for organizing the clinical data, and the HapMap, WTCCC and EGA groups for providing the high-quality dataset. This project was 
supported by the Taiwan National Research Program for Biopharmaceuticals (101CA1005).

\section{References}

1. Ferlay J, Shin HR, Bray F, et al: Estimates of worldwide burden of cancer in 2008: GLOBOCAN 2008. Int J Cancer 127: 2893-2917, 2010.

2. Yeh CT, Liang KH, Lin CC, Chang ML, Hsu CL and Hung CF: A single nucleotide polymorphism on the GALNT14 gene as an effective predictor of response to chemotherapy in advanced hepatocellular carcinoma. Int J Cancer 134: 1214-1224, 2014

3. Perz JF, Armstrong GL, Farrington LA, et al: The contributions of hepatitis B virus and hepatitis $\mathrm{C}$ virus infections to cirrhosis and primary liver cancer worldwide. J Hepatol 45: 529-538, 2006.

4. Liang KH, Lin CC and Yeh CT: GALNT14 SNP as a potential predictor of response to combination chemotherapy using 5-FU, mitoxantrone and cisplatin in advanced HCC. Pharmacogenomics 12: 1061-1073, 2011.

5. Venook AP, Papandreou C, Furuse J and de Guevara LL: The incidence and epidemiology of hepatocellular carcinoma: a global and regional perspective. Oncologist 15 (Suppl 4): 5-13, 2010.

6. Roberts RJ: How restriction enzymes became the workhorses of molecular biology. Proc Natl Acad Sci USA 102: 5905-5908, 2005.

7. Botstein D, White RL, Skolnick M and Davis RW: Construction of a genetic linkage map in man using restriction fragment length polymorphisms. Am J Hum Genet 32: 314-331, 1980.

8. Rommens JM, Iannuzzi MC, Kerem B, et al: Identification of the cystic fibrosis gene: chromosome walking and jumping. Science 245: 1059-1065, 1989.

9. Collins FS: Positional cloning: let's not call it reverse anymore. Nat Genet 1: 3-6, 1992.

10. Saiki RK, Scharf S, Faloona F, et al: Enzymatic amplification of beta-globin genomic sequences and restriction site analysis for diagnosis of sickle cell anemia. Science 230: 1350-1354, 1985.

11. Kwok PY: SNP genotyping with fluorescence polarization detection. Hum Mutat 19: 315-323, 2002

12. Liang KH, Fen JJ, Chang HH, Wang HW and Hwang Y: A base-calling algorithm for Tm-shifted melting curve SNP assay. J Clin Bioinforma 1: 3, 2011.
13. International HapMap 3 Consortium; Altshuler DM, Gibbs RA, Peltonen $\mathrm{L}$, et al: Integrating common and rare genetic variation in diverse human populations. Nature 467: 52-58, 2010.

14. Wellcome Trust Case Control Consortium: Genome-wide association study of 14,000 cases of seven common diseases and 3,000 shared controls. Nature 447, 661-678, 2007.

15. Bauer $\mathrm{CH}$, Vischer $\mathrm{P}$, Grünholz $\mathrm{H}$ and Reutter W: Glycosyltransferases and glycosidases in Morris hepatomas. Cancer Res 37: 1513-1518, 1977.

16. Mandel U, Hassan H, Therkildsen MH, Rygaard J, Jakobsen MH, Juhl BR, Dabelsteen E and Clausen H: Expression of polypeptide GalNAc-transferases in stratified epithelia and squamous cell carcinomas: immunohistological evaluation using monoclonal antibodies to three members of the GalNAc-transferase family. Glycobiology 9: 43-52, 1999.

17. Kohsaki T, Nishimori I, Nakayama H, Miyazaki E, Enzan H, Nomoto M, Hollingsworth MA and Onishi S: Expression of UDP-GalNAc: polypeptide $\mathrm{N}$-acetylgalactosaminyltransferase isozymes T1 and T2 in human colorectal cancer. J Gastroenterol 35: 840-848, 2000.

18. Wu YM, Liu CH, Hu RH, Huang MJ, Lee JJ, Chen CH, Huang J, Lai HS, Lee PH, Hsu WM, Huang HC and Huang MC: Mucin glycosylating enzyme GALNT2 regulates the malignant character of hepatocellular carcinoma by modifying the EGF receptor. Cancer Res 71: 7270-7279, 2011

19. Park JH, Nishidate T, Kijima K, Ohashi T, Takegawa K, Fujikane T, Hirata K, Nakamura Y and Katagiri T: Critical roles of mucin 1 glycosylation by transactivated polypeptide $\mathrm{N}$-acetylgalactosaminyltransferase 6 in mammary carcinogenesis. Cancer Res 70: 2759-2769, 2010.

20. Wagner KW, Punnoose EA, Januario T, et al: Death-receptor $\mathrm{O}$-glycosylation controls tumor-cell sensitivity to the proapoptotic ligand Apo2L/TRAIL. Nat Med 13: 1070-1077, 2007.

21. Thorburn A, Behbakht K and Ford H: TRAIL receptor-targeted therapeutics: resistance mechanisms and strategies to avoid them. Drug Resist Updat 11: 17-24, 2008.

22. WuC,GuoX,Wang W,etal:N-Acetylgalactosaminyltransferase-14 as a potential biomarker for breast cancer by immunohistochemistry. BMC Cancer 10: 123, 2010.

23. Obi S, Yoshida H, Toune R, Unuma T, Kanda M, Sato S, Tateishi R, Teratani T, Shiina S and Omata M: Combination therapy of intraarterial 5-fluorouracil and systemic interferon-alpha for advanced hepatocellular carcinoma with portal venous invasion. Cancer 106: 1990-1997, 2006. 